\title{
HELENA KOLODY: UMA TRAJETÓRIA INTELECTUAL QUE SE CONSTRÓI PELOS CAMINHOS DA POESIA E DA DOCÊNCIA
}

\begin{abstract}
RESUMO
Este artigo se propõe apresentar Helena Kolody (1912-2004), poetisa paranaense de grande sucesso no estado e reconhecimento entre o campo de letras no Brasil. Publicou cerca de 22 livros em sua carreira e ao fim do século XX teve um grande reconhecimento social com diversos prêmios e homenagens, como a entrada para Academia Paranaense de Letras. Com o objetivo de elucidar os caminhos formativos da intelectual pela docência, resgatando desta maneira a história do ensino normal entre os anos de 1930 e 1960 nas perspectivas da normalista e da professora do ensino Normal, busca-se responder de que forma a atuação na educação favoreceu o projeto intelectual de Kolody. As principais referências teóricas serão Jean François Sirinelli (1996), Maria Elizabeth Blanck Miguel (1997) (2008), Guacira Lopes Louro (1997) e Wilma de Lara Bueno (2003), usando também os conceitos de representação de Roger Chartier, poder de Michelle Perrot e paixão de Jane Soares de Almeida. Tendo por base estudos da nova história cultural a metodologia se refere à interlocução de fontes documentais inéditas e bibliográficas através da utilização de conceitos como, prosopografia de Giovanni Levi. Desta maneira os resultado e as conclusões do artigo puderam dar conta de que a docência favoreceu Kolody financeiramente e politicamente, proporcionando livre trânsito entre os campos da educação - passando pela docência e pela inspetoria de ensino - e o campo literário, caminhos pelos quais ela foi se constituindo como intelectual, produtora e mediadora cultural de relevo na sociedade paranaense.
\end{abstract}

Palavras Chave: Docência. Ensino Normal. Intelectual. Helena Kolody. Paraná.

\section{HELENA KOLODY: AN INTELLECTUAL TRAJECTORY THROUGH POETRY AND TEACHING}

\begin{abstract}
This article proposes to present Helena Kolody (1912-2004), poetess paranaense of great success in the state and recognition among the field of letters in Brazil. He published about 22 books in his career and at the end of the twentieth century had a great social recognition with several prizes and tributes, such as the entrance to the Academia Paranaense de Letras. With the objective of elucidating the formative paths of the intellectual by teaching, thus rescuing the history of normal teaching between the years 1930 and 1960 in the perspective of the normalist and the teacher of normal teaching, seeks to respond in what way the performance in education favored Kolody's intellectual project. The main theoretical references will be Jean François Sirinelli (1996), Maria Elizabeth Blanck Miguel (1997) (2008), Guacira Lopes Louro (1997) and Wilma de Lara Bueno (2003), also using the concepts of representation of Roger Chartier, power of Michelle Perrot and Jane Soares de Almeida's passion. Based on studies of the new cultural history, the methodology refers to the interlocution of unpublished documentary sources and bibliographies through the use of concepts such as Prosopografia by Giovanni Levi. In this way the results and the conclusions of the article could explain that the teaching favored Kolody financially and politically, providing free transit between the fields of education - passing through teaching and the teaching province - and the literary field, the paths by which it was Becoming an intellectual, producer and cultural mediator of prominence in the society of Paraná.
\end{abstract}

Keywords: Teaching. Normal Teaching. Intellectual. Helena Kolody. Paraná. 


\title{
HELENA KOLODY: UNA TRADICIÓN INTELECTUAL QUE SE CONSTRUYE POR LOS CAMINOS DE LA POESÍA Y LA DOCENCIA
}

\begin{abstract}
RESUMEN
Este artículo se propone presentar Helena Kolody (1912-2004), poetisa paranaense de gran éxito en el estado y reconocimiento entre el campo de letras en Brasil. En el siglo XX, en el siglo XX, tuvo un gran reconocimiento social con diversos premios y homenajes, como la entrada a la Academia Paranaense de Letras. Con el objetivo de elucidar los caminos formativos de la intelectual por la docencia, rescatando de esta manera la historia de la enseñanza normal entre los años 1930 y 1960 en las perspectivas de la normalista y de la profesora de la enseñanza Normal, se busca responder de qué forma la actuación en la educación Ha favorecido el proyecto intelectual de Kolody. Las principales referencias teóricas serán Jean François Sirinelli (1996), Maria Elizabeth Blanck Miguel (1997) (2008), Guacira Lopes Louro (1997) y Wilma de Lara Bueno (2003), utilizando también los conceptos de representación de Roger Chartier, Michelle Perrot y pasión de Jane Soares de Almeida. Con base en estudios de la nueva historia cultural, la metodología se refiere a la interlocución de fuentes documentales inéditas y bibliográficas, de la utilización de conceptos como, prosopografía de Giovanni Levi. De esta manera los resultados y las conclusiones del artículo pudieron dar cuenta de que la docencia favoreció a Kolody financieramente y políticamente, proporcionando libre tránsito entre los campos de la educación-pasando por la docencia y la inspectoría de enseñanza- y el campo literario, caminos por los cuales ella fue Se constituyó como intelectual, productora y mediadora cultural de relieve en la sociedad paranaense.
\end{abstract}

Palabras clave: Docencia. Enseñanza Normal. Intelectual. Helena Kolody. Paraná.

\section{INTRODUÇÃO}

Refletir sobre Helena Kolody (1912-2004), um nome consagrado da poesia paranaense do século XX, mas que para além dessa representação caracteriza um grupo de mulheres, atuantes e concentradas em torno de um projeto de reconhecimento do trabalho feminino como escritoras e docentes, é o caminho deste texto.

Utilizando o conceito de prosopografia ou biografia modal de Levi, "“[..] na verdade a biografia não é, nesse caso, a de uma pessoa singular e sim a de um indivíduo que concentra todas as características de um grupo.” (2006, p. 175). Consideramos que a trajetória de Helena Kolody, situando-a em seu tempo e espaço, e considerando suas relações de maneira dialógica dentro do espectro de mudanças constantes mesmo que recortada em alguns aspectos, pode contribuir para os estudos no campo da história da educação.

Portanto, o recorte do aspecto docente, se fez relevante por este estudo estar inserido na História da Educação e se apoiar nos conceitos de representação e poder que ao longo do texto se farão relevantes no alcance do objetivo maior de discutir a trajetória docente de Kolody problematizando seu apagamento nessa esfera a fim de elucidar os 
caminhos formativos da intelectual, para além da poetisa, compondo assim uma história que representa um grupo de mulheres paranaenses ligadas ao campo da educação e da literatura.

Por muitos séculos as mulheres foram ignoradas em sua condição de sujeitos históricos. Como cita Perrot (1988) estavam no campo dos excluídos da história. No Brasil, a inserção da mulher burguesa como profissional - que estuda e trabalha, constituindo uma carreira nesse processo - aconteceu somente a partir da segunda metade do século XIX, com mais acento a partir do século $\mathrm{XX}$, com o impulso do movimento feminista que começava a se organizar e o acesso ao ensino normal. Embora, o magistério não tenha sido o único caminho de profissionalização das mulheres burguesas, não se pode negar o papel fundamental que as escolas normais tiveram em sua formação e, consequente, em sua emancipação pela educação.

Para as mulheres a grande demanda pelo curso de formação de professores centrava em ser esta a única possibilidade de escolarização e profissionalização do período. Assim, o discurso normativo passou a ser acatado como forma de vencer barreiras sociais e resistências do segmento masculino. (ALMEIDA, 1998, p.133)

No caso do Paraná, algumas pesquisas como as de Pedro (1997) nos permite encontrar um perfil dessa mulher paranaense e burguesa nas primeiras décadas do século XX que utilizam da escrita e do magistério para começar a se inserir na sociedade. Podemos dizer que essas mulheres, moradoras da capital, viviam em contextos de representações sociais parecidos. Como cita Pedro,

os jornais sulistas no final do séc. XIX e início do séc. XX não criaram os modelos ideais de mulher como boas mães, virtuosas esposas e dedicadas filhas. Esses modelos já faziam parte do imaginário ocidental, podiam ser encontrados na literatura, no sermão das missas, nos textos escolares, nas tradições locais. (1997, p. 281)

Às mulheres eram atribuídas funções domésticas, era preparada para o lar, ser boa esposa e mãe, ela também era considerada um ser mais dócil que deveria se ater às questões religiosas e de caridade. Louro ainda complementa que, "através do símbolo mariano se apelava tanto para a sagrada missão da maternidade quanto para a manutenção da pureza feminina." (1997, p. 447) 
Nesse contexto, a instrução feminina sofreu a resistência social, no que tange ao direito e importância de mulheres frequentarem e se inserirem no meio educacional masculino, pois a intenção primeira era o casamento e a dedicação familiar. A aceitação só foi lentamente reconsiderada ao longo do início do século XX diante das necessidades encontradas pelos homens, como as guerras e a industrialização, situações em que a mão de obra masculina era essencial.

No Brasil, o período da primeira república exigia do País novas perspectivas para acompanhar o desenvolvimento industrial e ao mesmo tempo proporcionar o ensino, tendo professores e escolas para alfabetizar a população. Louro escreve,

o discurso sobre a importância da educação na modernização do país era recorrente. As críticas ao abandono educacional em que se encontrava a maioria das províncias estavam presentes nos debates do parlamento, dos jornais e até mesmo nos saraus. Os anos passavam, o Brasil caminhava para o séc. XX nas cidades povoadas, sem falar na imensidão rural, grande parte da população continuava analfabeta. (1997, p. 444)

Nesse cenário a mulher instruída aparece como um importante refúgio, mas era preciso considerar sua representação, proporcionando uma aceitação da sociedade diante de sua instrução e, consequentemente, de seu trabalho e circulação na vida pública. No estado do Paraná, em 1922, Lysimaco Ferreira da Costa, explica a importância da formação feminina na escola normal,

preparar a mulher paranaense que, à frente da sua escola será a continuadora da mulher-mãe que lhe entrega o filhinho querido para que seja guiado ao deixar o doméstico e santo lar, o cálido e terno regaço maternal, e iniciar-se ao cenário inquieto e ruidoso da escola, em que, somente, a suavidade e afeição da mulher-mestra poderão tornar menos sensível essa primeira e brusca transição da vida social da criança. (COSTA, 1987 p. 120)

No Paraná, assim como em todo Brasil os desafios diante do crescimento econômico e social, para o atendimento da população se fazia crítico. Além da educação, como cita De boni (1998), "outro Desafio da época, posto para o prefeito de Curitiba, foi a reurbanização desta cidade, capital do estado. Esta cidade possuía 50.124 habitantes em 1900. Vinte anos depois Curitiba abrigava 78.986 habitantes.” (Apud ROCHA 2003, p.153).

Assim, pode-se inferir que a presença feminina nas escolas veio das necessidades que o País e cada estado - dentre eles, o Paraná- sofreram. Dessa maneira, as modificações 
da representação feminina para o trabalho sofreram influências do projeto de crescimento da nação através do contexto de necessidade educacional, bem como de necessidade do crescimento econômico, com mão de obra masculina em outros setores.

As questões que são postas diante desse período vão se alterando conforme necessidades maiores vão surgindo e a demanda educacional é um exemplo. Diante de uma sociedade que se modernizava em produção econômica, as mulheres começam a ocupar lugares antes masculinos, como é o caso do ensino primário. Segundo Bueno,

era necessário educar as mulheres para uma sociedade que se modernizava, possibilitando-lhes o acesso à educação e aos direitos políticos. Essas conquistas atemorizavam a sociedade no sentido de que pudessem afetar o perfil feminino e comprometer as relações afetivas e familiares. (2003, p. 207)

A inserção profissional feminina no magistério foi aos poucos trazendo um novo perfil para a educação. A sociedade agora presenciava mulheres sob uma nova, mas nem tão diferente, perspectiva. Louro cita,

a saída dos homens das salas de aula - dedicados agora à outras ocupações, muitas vezes mais rendosas - legitimava a entrada das mulheres nas escolas - ansiosas para ampliar seu universo - restrito ao lar e à Igreja. A partir de então passam a ser associadas ao magistério atitudes tipicamente femininas: paciência, minuciosidade, afetividade, doação. [...] Tudo foi muito conivente para que se constituísse a imagem das professoras como trabalhadoras e dóceis, dedicadas e pouco reivindicadoras, o que serviria futuramente para lhes dificultar a discussão de questões ligadas a salário, carreira, condições de trabalho. (1997, p. 450)

É perceptível que aos poucos a mulher foi se inserindo no magistério e quando conveniente foram utilizadas como profissionais pelo estado. Segundo Louro, "as escolas normais se enchem de moças. A princípio são algumas, depois muitas; por fim os cursos normais tornam-se escolas de mulheres." (1997, p. 454). Um ponto a ser considerado é a ascensão que a formação para o magistério permitia a essas mulheres ao mundo da escrita. Embora nem sempre essa acontecesse nessa ordem, como foi o caso de Helena Kolody, essa formação servia como dispositivo de legitimação e impulsionava voos mais altos. Segundo Bueno,

a acentuada presença dessas jovens normalistas no universo da poesia nos leva a constatar o significado das escolas de magistério para a mulher 
ascender ao mundo da escrita, e desta forma, viabilizar possibilidades para expressar opiniões, ideias e projetos intelectuais. (2003, p. 212)

O acesso à educação levou muitas dessas mulheres a criarem redes de sociabilidade e se associarem em grupos que serviam para dar voz e maior legitimidade a projetos intelectuais, artísticos e/ou sociais. Nos anos 30, um grupo de mulheres curitibanas organizou uma associação feminina que serviria para produzir um reconhecimento de suas associadas no campo da cultura. Bueno escreve,

em Curitiba, por volta de 1930, jovens universitárias, adeptas de opiniões acerca da modernização do papel da mulher na sociedade, reuniram-se ao redor da ideia de constituir um centro que tivesse como principal objetivo investir no aprimoramento intelectual, artístico e desportivo da mulher paranaense. Com essa finalidade, criaram o Centro Paranaense de Cultura Feminina ${ }^{1}$ no dia 05 de Dezembro de 1933. (2003, p. 210)

Se alguns já se assustavam com a mulher indo ao trabalho, nos anos 1930, as mulheres passam a se reunir para falarem de seus anseios e compartilharem cultura. Tal fato mostra-se de grande relevância para a história feminina no Paraná. Independentemente de serem casadas, algumas mulheres da burguesia curitibana passaram a frequentar, paulatinamente, espaços sociais onde podiam expor sua opinião e, ao poucos, foram alcançando outros espaços de expressão e conhecimento. Para Trindade,

na tríade família, sociedade e pátria, a educadora curitibana situa os níveis sucessivos de participação daqueles a quem a escola republicana concede o direito e cobra o dever de educar-se. Na mulher republicana a escola pretende desenvolver atributos que a tornem apta a exprimir uma face interna e intimista, voltada a manutenção da unidade familiar, e uma figura externa e pública que preencha os interesses da sociedade e da Nação. (1996, p. 31)

Ocupar lugares exclusivamente masculinos, para muitas mulheres, iniciou-se como já visto pela escola normal. Muitas atuaram na docência, outras, não. Mas, ao longo da história, esse foi um dos caminhos que, sem dúvida, permitiu às mulheres conquistarem outras profissões e espaços na sociedade. A educação foi a porta de entrada para a mulher burguesa na cena pública, até mesmo na criação do Centro. Como cita Bueno,

\footnotetext{
${ }^{1} \mathrm{O}$ nome da instituição em questão se oficializou posteriormente para Centro Paranaense Feminino de Cultura (CPFC)
} 
os dados indicam que grande parte delas teve sua formação nas escolas de magistério, criadas no Paraná e se ocupou de atividades relacionadas ao ensino, como fundar escolas, ministrar aulas e inspecionar ensino. Essas incidências chamam a atenção do pesquisador no sentido de constatar que o magistério era também uma possibilidade de inserção das mulheres no seio da intelectualidade paranaense, com desdobramentos para a produção literária e, particularmente, para o campo da poesia. (2003, p. 213)

A literatura foi outro campo pelo qual as mulheres expressaram seus sentimentos, opiniões e visões de mundo, intervindo deste modo na produção estética e cultural de seu tempo. Foi também o caminho pelo qual muitas dessas mulheres tornaram-se reconhecidas como intelectuais no meio curitibano. Nesse sentido, as escolas de formação para o magistério e a vinculação à associações como o Centro Paranaense Feminino de Cultura foram fundamentais. E Helena Kolody utilizou essas duas portas na construção de sua trajetória intelectual. Neste texto, no entanto, o nosso recorte recai sobre a docência.

Portanto, a fim de discutir a trajetória docente de Kolody problematizando seu apagamento e elucidando os caminhos formativos da intelectual pela atuação na educação utilizaremos de fontes documentais públicas e inéditas. As fontes já publicadas referem-se a algumas entrevistas em jornais paranaenses, e as inéditas, são ATAS do Instituto de Educação do Paraná - escola de formação de professores da capital -, bem como, os documentos funcionais de Helena Kolody enquanto servidora pública do estado ${ }^{2}$.

\section{POR QUE HELENA KOLODY?}

Encontrar mulheres intelectuais que possuem suas bases ancoradas na educação é comum, entretanto, a partir de novas representações sociais, ocorre um apagamento de sua carreira docente. Para Almeida, "atualmente, a história das mulheres constitui um campo de estudos bastante privilegiado, mas as mulheres, enquanto profissionais do ensino, tem sido constantemente relegadas ao esquecimento. (1998, p. 25)

Kolody já fora muito estudada no campo da linguística com dissertações e teses sobre seu trabalho poético, sua vida até surge em segundo plano, entretanto sua carreira

${ }^{2}$ Esses documentos estavam sob a guarda do estado e até o momento não haviam sido liberados para pesquisa. Talvez, por essa razão, pouco tenha se discutido sobre a atuação de Helena Kolody como professora. A ausência de fontes ou a indisponibilidade das mesmas, de certo modo, pode ter contribuído para a produção de uma representação desta mulher vinculada quase que exclusivamente ao campo da literatura. 
docente, assim como na imprensa paranaense só ganha espaço com poucas informações, como se a docência fosse uma doação para a poetisa.

Helena foi a primeira filha brasileira de seus pais imigrantes Ucranianos, mas diferente de algumas famílias imigrantes que acabaram submetendo seus filhos ao trabalho exploratório nas fábricas, o que aconteceu com a família Kolody foi o incentivo para que Helena e os irmãos estudassem e constituíssem carreira.

[...] Então a gente estudava e eu pensava 'tenho que dar para o papai essa alegria' porque ele queria que nós estudássemos. Os nossos vizinhos Ucranianos diziam ao papai 'Helena tem que trabalhar na fábrica' - pois trabalhavam na fábrica de fitas - Mas papai dizia 'Não! Ela vai estudar'. (KOLODY, 1998, p.24)

A representação da mulher que estuda e segue uma carreira, é diferente segundo sua classe social, seus objetivos, e a percepção de sua família, o que se pode inferir neste caso é que a instrução, principalmente, para uma mulher imigrante representava uma perda de dinheiro, já que mulheres e crianças mais pobres trabalhavam, mesmo que em condições precárias, para ajudar no sustendo da família. Diante desse cenário, nasceu uma certa "simpatia" com esta mulher que viria a tornar-se nosso objeto de pesquisa. Sirinelli escreve,

para o historiador dos intelectuais, muito particularmente, coloca-se o problema da simpatia. Esta, no sentido primeiro do termo, é necessária; constitui mesmo a essência do ofício do historiador. Resta contudo o sentido comum e, nesse registro, sem dúvida alguma, simpatias nascem, antipatias crescem, o todo acompanhando as curvas da evolução eventual do pesquisador. Mais que ocultar o fenômeno, sem dúvida é preciso tomar plena consciência dele, assumi-lo de algum modo, a fim de avaliálo. $(1996$, p.239)

Problematizando as representações que hoje nos são apresentadas, muitas delas nos intrigam, como o fato da representação da intelectual Helena Kolody estar restrita a sua profissão de poetisa. A ausência de fontes de sua vida como professora e inspetora federal do ensino secundário nos motiva a compreender melhor suas contribuições na educação, entre os anos 30 e 60 no estado do Paraná, considerando a história da educação como um “campo aberto", tal como afirmam Lopes e Galvão: 
atualmente, pode-se falar de forma mais apropriada em histórias da educação, pois as investigações que vêm sendo realizadas no campo não se restringem mais ao ensino e pensamento pedagógico, objetos tradicionais da disciplina. A aproximação da história da educação com outras ciências humanas e com outras áreas da história contribuiu para que as crianças e os jovens, os intelectuais, o livro e a leitura, as mulheres, etc. também se tornassem objeto da disciplina. (2012, p. 41)

Nesse caminho é possível considerar as fontes relacionadas ao campo educacional no qual nossa intelectual atuou como expressão de estratégias que mobilizaram a construção de uma representação e autorrepresentação de si e/ou de seu projeto. Como cita Chartier,

o porquê da importância da noção de representação, que permite articular três registros de realidade: por um lado, as representações coletivas que incorporam nos indivíduos as divisões do mundo social e organizam os esquemas de percepção a partir dos quais eles classificam, julgam e agem; por outro, as formas de exibição e de estilização da identidade que pretendem ver conhecida; enfim, a delegação a representantes (indivíduos particulares, instituições, instâncias abstratas) da coerência e da estabilidade da identidade assim afirmada. (2002, p. 11).

É perceptível que o conjunto de trabalhos, especificamente sobre mulheres, vêm crescendo. Segundo Lopes e Galvão "sentimentos, emoções e mentalidades passam a fazer parte da história" (2012, p. 32). E nesse caminho, este artigo pretende contribuir com o campo da história da educação sobre a intelectualidade feminina, refletindo sobre o modo como o campo da educação no Paraná favoreceu à projeção intelectual de Helena Kolody em uma relação que se constituiu como via de mão dupla.

Em suas entrevistas, Helena Kolody fala da sua paixão pelo trabalho, "nasci professora e sempre amei ser professora! A poesia foi um canteiro de flores que nasceu à beira do meu caminho do magistério" (KOLODY, 1998, p.26). Suas frases poéticas, até mesmo quando concedia entrevistas, principalmente quando estas deixavam claros seus objetivos, enveredam pelo lado da paixão que viveu com o magistério, favorecendo assim a produção de uma representação da professora que se doava pelo amor a sua carreira, alunos e sociedade.

Mas, pode-se dizer que nem só de paixão ela subsiste. No caso da docência, sobretudo, é uma escolha permeada de muitos sentidos, dentre eles, o sentido político. Assim a pesquisa sobre as mulheres tem contribuído para desmistificar muitos aspectos historicamente reproduzidos. Como cita Perrot, 
a pesquisa feminista recente por vezes contribuiu para essa reavaliação do poder das mulheres. Em sua vontade de superar o discurso miserabilista da opressão, de subverter o ponto de vista da dominação, ela procurou mostrar a presença, a ação das mulheres, a plenitude de seus papéis, e mesmo a coerência de sua cultura e a existência de seus poderes. (1988, p.169-170)

Seguindo neste texto a indicação de Perrot "o que importa reencontrar são as mulheres em ação, inovando em suas práticas, mulheres dotadas de vida, e não absolutamente como autômatas, mas criando elas mesmas o movimento da história." (1988, p.187). Para tanto, os documentos funcionais disponibilizados pela secretaria de educação do Paraná e que hoje fazem parte da divisão de documentação do Estado do Paraná se fazem relevante.

Helena Kolody foi conhecida nacionalmente por seu trabalho como poetisa, mas aposentou-se como professora normalista do estado do Paraná e inspetora federal do ensino secundário, o que lhe rendeu ganhos financeiros, trânsito em funções diversas no campo da educação, e principalmente, reconhecimento do seu trabalho pelo Estado.

\section{A DOCÊNCIA EM HELENA KOLODY}

Sobre sua formação educacional e sua atuação docente, apesar da paixão, Helena fala pouco em algumas entrevistas que concedeu a jornais e revistas quando tornou-se reconhecida por seu trabalho como poetisa. Ainda hoje são essas as únicas fontes públicas que estão reunidas no acervo de documentação da Biblioteca Pública do Paraná. De suas memórias, Helena destaca:

eu fiz o primário do tempo em que Prieto Martinez, fez a reforma, um dado histórico, este. Então em Rio Negro aconteceu uma coisa que hoje não fazem mais. O Grupo do Rio Negro era um dos melhores do Paraná[..] Então era assim, se a gente dava conta de uma série, no meio do ano a gente passava pra a seguinte. Eu fiz o Grupo em três anos. (KOLODY, Revista Quem, 1980, p. 19)

Helena não especifica o ano de sua passagem como aluna do Grupo Escolar de Rio Negro. Sabemos que nasceu em 1912, na cidade de Cruz Machado, o que significa que pode ter estudado no grupo entre os anos de 1920. Como já citado, seu pai a incentivou a estudar, pois viviam em uma cidade do interior, na qual habitavam muitos imigrantes, como eles, que fugiram da guerra na Europa e se estabeleceram como puderam em busca de sustentar suas famílias e constituir nova moradia e emprego. 
Já moça, com quinze anos, Helena e a família foram viver em Curitiba, especificamente na capital, com moradia próxima ao centro. Em 1927, ela entrou para a Escola de Professores de Curitiba, atual Instituto de Educação do Paraná ${ }^{3}$. Sobre sua decisão de ser uma normalista, "o fascínio pelos livros, me levou a Escola Normal de Curitiba - uma das poucas opções para mulheres que se interessavam pelos estudos, na época." (KOLODY, Revista Helena, 2012, p.27).

Essa frase, "uma das poucas opções para mulheres" remete ao início desse artigo quando discutíamos as opções de ascensão social e profissional das mulheres no Paraná nos primeiros anos do século XX.

Em relação ao campo da educação, estavam acontecendo no Paraná naquele momento um conjunto de reformas educacionais que deveriam dar novos rumos tanto para a escola primária quanto para a escola normal. Prieto Martinez se incumbiu das reformas no ensino primário. Segundo Miguel,

O governo trouxe para ocupar o cargo de Inspetor Geral do Ensino o então diretor da Escola Normal de Pirassununga[...] É possível identificar, nas idéias que moveram a ação educacional de Prieto Martinez, a lógica racionalizadora do trabalho industrial e a valorização do homem como recurso humano para o progresso da nação. (1997, p.27)

Mas, com relação à concepção pedagógica adotada pelo ensino normal no Paraná, vemos uma outra influência pedagógica, que marca e distingue a educação para os alunos que chegavam a este nível de ensino, mas também apresenta um modernismo conservador que postula novos métodos sem romper totalmente com as heranças da Pedagogia Moderna do final do século XIX, especialmente de matriz Herbartiana. Sobre isso, Miguel afirma:

o curso especial compreendia principalmente as metodologias que seguiam a pedagogia de Herbart, e eram ministradas de acordo com os passos formais dessa pedagogia. A leitura de Herbart foi aplicada segundo a compreensão que dela tiveram dois pedagogos argentinos: Patrascoiu e Pablo Pizzurno, os quais Lysímaco conheceu em viagem à Argentina para comercializar erva-mate. Deste modo, se o conjunto da reforma educacional paranaense empreendida por Martinez teve a influência racionalizadora da sociedade industrial paulista nascente, a reforma na Escola Normal recebeu influência mais tradicional, uma vez que a pedagogia de Herbart na visão dos pedagogos citados, era segundo Erasmo Pilotto, bastante ultrapassada. Porém, segundo o mesmo Pilotto,

\footnotetext{
${ }^{3}$ O Instituto de Educação do Paraná será aqui tratado também pela sigla IEP, em fontes também pode ser lido
} como Escola de Professores da Capital e Escola de Ensino Normal. 
"isso, porém, não deve diminuir a importância da reforma que devemos a Lysímaco Ferreira da Costa” (2008 p.14)

Foi nesse cenário pedagógico que buscava aliar tradição e modernidade no campo pedagógico que Helena Kolody se formou. Um dos grandes orgulhos de Helena era dizer que tinha sido a primeira aluna de sua turma, e até mesmo isto a favorece posteriormente em sua carreira. O Curso Normal era dividido em geral ou fundamental, em três anos e o curso especial ou profissional, em três semestres.

QUADRO 1 - Notas dos exames finais do curso especial de 1930, $1^{\circ}$ semestre

\begin{tabular}{|c|c|c|c|c|}
\hline \multicolumn{5}{|c|}{$1^{\mathbf{0}}$ semestre do $\mathbf{4}^{\mathbf{0}}$ ano do curso especial } \\
\hline $\begin{array}{c}\text { Metodologia } \\
\text { da Leitura e } \\
\text { Escrita }\end{array}$ & $\begin{array}{c}\text { Metodologia } \\
\text { Geral }\end{array}$ & $\begin{array}{c}\text { Higiene e } \\
\text { Agronomia }\end{array}$ & Psicologia & Metodologia \\
\hline 10 & 10 & 9,7 & 10 & do Desenho \\
\hline
\end{tabular}

Fonte: ATA do IEP em posse do Arquivo Público do Paraná.

Metodologia do desenho não teria sido o forte de Helena Kolody, sendo sua nota mais baixa. Já metodologia da leitura e da escrita, como já esperado por ser uma poetisa, tirou nota máxima, assim como em metodologia geral e psicologia, as quais por curtos períodos seriam matérias lecionadas por ela posteriormente.

QUADRO 2 - Notas dos exames finais do curso especial de 1930, $2^{\circ}$ semestre

\begin{tabular}{|c|c|c|c|c|c|}
\hline \multicolumn{7}{|c|}{$\mathbf{2}^{\mathbf{0}}$ semestre do 4'ano do curso especial } \\
\hline \multirow{2}{*}{$\begin{array}{c}\text { Metodologia } \\
\text { de Aritmética }\end{array}$} & $\begin{array}{c}\text { Metodologia } \\
\text { de Geografia }\end{array}$ & $\begin{array}{c}\text { Metodologia } \\
\text { de Ciências }\end{array}$ & $\begin{array}{c}\text { Moral e } \\
\text { Educação }\end{array}$ & $\begin{array}{c}\text { Método do } \\
\text { Ensino }\end{array}$ & $\begin{array}{c}\text { Metodologia } \\
\text { do Vernáculo }\end{array}$ \\
\hline 10 & 10 & 9,8 & 10 & 9,3 & 9,8 \\
\hline
\end{tabular}

Fonte: ATA do IEP em posse do Arquivo Público do Paraná.

Duas disciplinas importantes posteriormente na carreira de Helena não foram suas maiores notas. Na disciplina de metodologia de ciências naturais, ficou com 9,8, apesar 
desta disciplina ter ligação direta com a biologia educacional, matéria que seria de Kolody em sua carreira docente, foi uma das poucas disciplinas que não foi a $1^{\mathrm{a}}$ da turma, ficando abaixo de outras duas colegas.

Já na disciplina de método do ensino intuitivo, uma grande questão do momento, que futuramente lhe exigiria pesquisas mais detidas, ela foi avaliada com 9,3 apesar de ser a segunda nota mais baixa da normalista, ainda foi a maior da turma, trazendo também mérito à Helena.

QUADRO 3 - Notas dos exames finais do curso especial de $1931,1^{\circ}$ semestre.

\begin{tabular}{|c|c|c|c|}
\hline \multicolumn{4}{|c|}{$\mathbf{1}^{\mathbf{0}}$ semestre do 5'ano do curso especial } \\
\hline $\begin{array}{c}\text { Metodologia de } \\
\text { Música }\end{array}$ & $\begin{array}{c}\text { Ensino dos Trabalhos } \\
\text { Manuais }\end{array}$ & $\begin{array}{c}\text { Prática e Critica } \\
\text { Pedagógica }\end{array}$ & $\begin{array}{c}\text { Metodologia dos } \\
\text { Exercícios Físicos }\end{array}$ \\
\hline 10 & 10 & & Distinção \\
\hline
\end{tabular}

Fonte: ATA do IEP em posse do Arquivo Público do Paraná.

Das quinze matérias que Kolody frequentou na modalidade especial do curso normal pode-se perceber dedicação em todas, com nota máxima em oito disciplinas pudemos chegar à conclusão que era mesmo a primeira de sua turma, sendo 9,0 sua nota mais baixa. O endosso do secretário que abordaremos adiante também reforça essa distinção.

Apesar de Kolody ter se formado em Curitiba, e alguns anos depois ter sido professora da mesma escola, sua carreira como Professora Paranaense passa por alguns caminhos. "E quando eu me formei em 1931, fui para Rio Negro, casa da minha tia, porque tinha que ir para o interior; eu não tinha pistolão.” (KOLODY, Caderno MIS, 1989, p. 22).

Helena então foi trabalhar em um grupo escolar, no interior do Paraná, mesma cidade onde cursou o ensino primário. Com formação na Escola Normal Secundária da capital, seu primeiro cargo foi como professora adjunta, 
fui nomeada para Rio Negro;[..] fui como adjunta da professora América Sabóia; depois vim a diretoria de ensino, e digo por que não saiu minha nomeação? Tem que esperar, porque é que não tem vaga[..] fui a escola normal, o secretário que era sr Julio da Luz[..] disse: olha Helena, vou dar um conselho, você pegue sua certidão de notas, você foi a primeira aluna da turma,[...] que seu pistolão sejam suas notas[...] No outro mês eu estava nomeada. Quer dizer que também eles sabiam fazer justiça, que eu lá em Rio Negro era desconhecida, filha de imigrantes, não estavam sabendo quem era, assim viram pela nota, assim eu sabia dar conta do meu recado. Daí então, lecionei até o final do ano em Rio Negro, e nesse tempo, e essa certidão de nota me valeu depois por diante. (KOLODY, Caderno MIS, 1989, p. 23)

Segundo Miguel "os melhores alunos[...] foram enviados as outras escolas de professores implantadas, com a missão de reproduzir o que haviam aprendido. Dessa forma, as escolas rurais constituíram-se importante campo de ação dos professores" (1997, p.93). Era como um teste e ao mesmo tempo uma confiança depositada aos novos professores, Helena cumpre sua estada e vai aos poucos conseguindo o que desejara primeiro, que era se estabelecer trabalhando na capital paranaense, na escola onde se formou.

Em 1933, logo após ser nomeada, Kolody acaba herdando a cadeira de um professor em Ponta Grossa "o professor Erasmo Piloto[...] veio para cá lecionar, e ficou vaga a cadeira. Como eu tinha sido a primeira aluna me levaram para lá. Com 20 anos eu era professora da Escola Normal de Ponta Grossa." (KOLODY, Caderno MIS, 1989, p. 24).

O professor Erasmo Piloto, importante intelectual no meio educacional paranaense, atualmente patrono do Instituto de Educação do Paraná, tornou-se colega de Kolody, e ocupar a sua vaga em Ponta Grossa acabou sendo a primeira de algumas vezes que ela o substituiu. Em Ponta Grossa,

as alunas eram mais velhas que eu, porque tinham 15 mais moça do que eu das 60[..] elas eram professoras com 15, 20, mais anos de serviço e vieram fazer curso especial; comigo, Então o medo que eu tinha! Estudava até meia noite! Então mandei buscar livros em São Paulo, no Rio de Janeiro, até, através do Rio de Janeiro, na Espanha. Sobre Escola Nova que eu não sabia. (KOLODY, Caderno MIS, 1989, p. 24). ${ }^{4}$

\footnotetext{
${ }^{4}$ É curioso pensar na circulação de modelos pedagógicos e dos enunciados da Escola Nova no Brasil, a partir de diferentes fontes. O uso de livros vindos da Espanha, ao invés dos Estados Unidos, França, Bélgica ou Suiça - tradicionalmente apropriados pelas diferentes matrizes do campo pedagógico - nos instiga a pensar
} 
Além da pouca idade e da responsabilidade que assumira, tinha a incumbência de conhecer, utilizar e difundir um novo método de ensino. Ela exemplifica,

\begin{abstract}
Aquela sempre responsabilidade. Mas ao mesmo tempo o amor pelo magistério, aquelas descobertas de coisas novas dentro do magistério. Mas, com isso pode ser feito assim, e depois a alegria de ver que aquilo dava certo na prática. Que elas faziam e havia aquele entusiasmo das crianças e tudo de trabalhar, porque era uma escola ativa, chama-se Escola Ativa, onde as crianças, por exemplo: fazer uma redação, não fazia passivamente. Então agora você é repórter, era o método de Munich então elas saiam (KOLODY, Caderno MIS, 1989, p. 24).
\end{abstract}

Helena trabalha nesse período com psicologia, 'em 1933, foi nomeada para reger a cadeira de psicologia e pedagogia da Escola Normal de Ponta Grossa.” (KOLODY, 1976, Revista Rumo Paranaense, s/pág.) Nesse sentido é compreensível que cite o método de munich, mas a escolha desse método é também indicativa do seu diálogo no campo pedagógico, uma vez que essa corrente se refere a uma apropriação católica do movimento escolanovista. Orlando (2008), em sua análise sobre os livros didáticos de catecismo do padre Álvaro Negromonte, o qual também fez sua leitura do movimento escolanovista com base neste método, explica:

método munich, indutivo, também chamado de método psicológico. A este[..] estão ligados todos aqueles que defendem o ensino religioso de acordo com os avanços da pedagogia moderna e não se abstém da influência de outros métodos modernos como os centro de interesse de Decroly, o método de projetos de Montessori, a educação funcional de Claparède. (p. 196)

Essa leitura católica da escola nova possui uma marca de diálogo com o novo, com o moderno, especialmente pela psicologia, mantendo a indução que é uma das características da pedagogia de Herbart, não rompendo totalmente com modelos pedagógicos anteriores. Ao contrário, havia nesse modelo uma junção de concepções que buscava extrair de cada uma aquilo que oferecessem de melhor. Do ponto de vista prático, em outra entrevista Helena exemplifica como a redação poderia ser trabalhada nesse método ativo,

em Ponta Grossa, eu fui professora de metodologia e, naquele tempo, as crianças viam as coisas passivamente [...] eu estudei e aprendi um método ativo. Então, chegava na sala, pegava os alunos e dizia "Agora vocês são

nos modelos que circularam no Paraná. Os livros que ela leu, no entanto, não foram identificados até o momento e essa é uma questão que continua aberta. 
repórteres e vão fazer uma entrevista, sem barulho". Eles saiam de lápis e papel na mão e iam entrevistar a diretora, a cantineira ou alguém que estava entrando na escola, uma porção de gente... Enchiam, ás vezes, duas páginas e traziam para sala de aula. (KOLODY, 1998, p.26)

Helena traz em sua carga de memória a atuação com o método ativo como um importante fator no início de sua carreira. Ter tido esta formação e poder mediá-la na formação de professores demonstra uma dedicação em estar em consonância com seu tempo, alinhada a projetos pedagógicos em voga, demonstrando atualidade e competência profissional. Ainda sobre o método ativo, Miguel escreve,

a pedagogia da Escola Nova consolidou-se na formação do magistério[...] dava-se relevância ao aluno como centro do processo de ensinoaprendizagem, à metodologia ativa, à ação educacional pautada nos avanços científicos da Psicologia, da Biologia e da Sociologia. (1997, p.92)

Psicologia foi a primeira disciplina que Kolody ministrou, na qual obteve excelente rendimento na sua avaliação final do curso especial, se formando com nota 10. Entretanto, posteriormente a biologia educacional seria seu campo mais atuante. Tal período em Ponta Grossa terminara em 1937, ano em que Helena retomou à capital. "Em 1937 passou a lecionar na Escola Normal de Curitiba, estabelecimento onde foi professora 23 anos" (S/ Autor, 1976, Revista Rumo Paranaense, s/ pág.).

Neste período no Instituto de Educação do Paraná, Helena conviveu com diferentes pessoas, voltou ao seu círculo de convivência de quando era normalista e foi dando outros passos em seu projeto de reconhecimento intelectual. Com a análise dos seus documentos funcionais, de 1943 à 1961 foi percebido uma ascensão profissional, com passagem por diferentes cargos e funções, o que paulatinamente foi tornando-a cada vez mais reconhecida no seu trabalho. Ser professor, segundo Vilela e Gasparello,

uma profissão intelectual que não os afastava do grupo de letrados, mas que agregava uma conotação específica - o ofício de ensinar - com suas funções correlatas: produzir livros didáticos, relatórios, participar de bancas de exames, respondendo ao desafio constituído por demandas institucionais, burocráticas, pedagógicas e sociais que confluíam para o campo do ensino. (Vilela e Gasparello 2009, p.56)

Desta maneira, Helena foi crescendo na profissão. De professora normalista de $2^{\mathrm{a}}$ classe da escola de professoras da capital passou à professora catedrática do ensino médio 
padrão U na cadeira de biologia educacional. E dentre as funções que desempenhou no auge de sua carreira no IEP, podemos destacar: avaliadora de concursos para professor auxiliar, parecerista de cartilha, fiscal das escolas normais livres, parecerista sobre organização do ensino normal no estado e assistente técnica em substituição de Erasmo Piloto.

Helena declarou em algumas entrevistas a matéria que lecionara "sempre lecionei biologia, há coisas mais fascinantes que a vida? “(KOLODY, 1980, Revista Quem, p. 20). $\mathrm{O}$ amor à disciplina de Biologia é perceptível em sua poesia. A dificuldade com a disciplina de literatura, no entanto, é uma surpresa,

eu nunca fui professora de Literatura. Lecionei Biologia. Tanto que, se você e fizer uma sabatina de Teoria Literária, eu tiro um zero bem redondo. [..] A poesia só me serviu para chantagear minha alunas. Eu dizia: se fizerem um exercício tal de genética, eu declamo um poema para vocês. Elas adoravam. (KOLODY, 1985, Jornal do Livro, p. 5)

No IEP além de Kolody ter sido professora de Biologia Educacional foi também de: geografia do brasil e geral, anatomia e metodologia. Antes de aposentar em 1961, ela ainda atuou como inspetora federal do ensino secundário,

paralelamente as atividades do magistério, exerceu as funções de Inspetora Federal do Ensino Secundário, após ter sido aprovada em concurso de títulos e provas DASP. Nessas condições prestou serviços junto a diversos estabelecimentos de ensino secundário em Curitiba; exerceu as funções de Secretária do Fundo Nacional de Ensino Médio e mais tarde as de Inspetora Itinerante da Inspetoria Seccional de Curitiba. (S/ Autor, 1976, Revista Rumo Paranaense, s/ pág.)

Por meio dos acompanhamentos, das fiscalizações e dos relatórios Helena pôde participar, do outro lado, de uma forma igualmente ativa, do desenvolvimento da educação no Paraná até a década de 60. Referente a importância desses documentos Miguel escreve, "estes documentos oficiais sejam eles leis ou relatórios dos presidentes da província, e mais tarde dos governadores do Estado, bem como os relatórios dos inspetores, manifestam a visão institucional[..]” (2008, p.1).

Sobre o ingresso nesse cargo era necessário uma titulação acrescida de aprovação no concurso. Para Helena o que valeu foi já ter publicado seu primeiro livro de poesias em 1945. “O Inspetor na época era o professor padre João Camargo. Ele aconselhou-me e 
orientou-me para o concurso. Então inscrevi no MEC o meu livro paisagem interior como título. Foi o que me valeu." (KOLODY, 1980, Revista Quem, p. 19).

Os trabalhos de Kolody ao IEP foram reduzidos desde o ano de 1952, até que em 1958 seus dados funcionais trazem o termo 'cooperativa mixta' referindo-se a sua atuação como professora com apenas 2 aulas semanais de professora de Biologia Educacional e o cargo de inspetora federal. E em 28 de Agosto de 1961 Ney Braga e Mario Braga Ramos assinam a aposentadoria de Helena Kolody como professora do estado do Paraná. A essa altura ela já era uma figura pública de relevo na cultura paranaense. Paralelamente ao ofício docente escreveu poesias e as publicou nos jornais, teceu redes no campo da educação e da literatura, marcou sua geração pela sensibilidade estética de sua poesia e fez ecoar na cena pública uma voz feminina forjada entre dois ofícios: o de escritora e professora.

\section{CONSIDERAÇÕES FINAIS}

Helena Kolody sempre escreveu. Desde sua adolescência já era conhecida por seus próximos como poetisa, mas soube pelo seu pai a importância da instrução, percebeu que ser professora era um caminho de sustento financeiro. Em meio aos seus projetos mostrou poder quando utilizou de seu desempenho como primeira aluna de sua turma para ser nomeada professora pelo estado. Partindo daí constituiu uma carreira composta de inúmeras alunas, algumas cidades diferentes e em poucos anos retorna a escola que a formou.

Helena Kolody atuou em um magistério marcadamente feminino, mas em sua maioria comandado por homens, como no Instituto de Educação do Paraná cujo diretor era o professor Erasmo Piloto. Seus caminhos se cruzaram algumas vezes e, por força do acaso ou não, sua aproximação com este intelectual lhe rendeu algum prestígio. Se as duas vezes que substituiu o professor parecem ter sido uma feliz coincidência, não podemos esquecer que, em ambos os casos, eram cargos preenchidos por indicação. Para Vilela e Gasparello,

uma situação que leva a marca da sociedade hierárquica e dominada por homens: as professoras situadas em patamar inferior ao status de intelectuais, sendo principalmente reconhecidas pela maior ou menor proximidade social com os indivíduos que se notabilizavam por funções de autoridade política ou intelectual. (2009, p.56) 
Helena Kolody participou ativamente da história do ensino secundário do Paraná e é notório o apoio que recebeu de alguns homens, intelectuais representativos de diferentes grupos como o Padre João Camargo e o Professor Erasmo Piloto. O apoio da rede a qual pertencia certamente serviu não apenas para ocupar lugares de destaque no campo da educação, mas também como estratégia de legitimação para o seu reconhecimento no campo das letras.

Seus primeiros livros foram publicados por conta própria e ter usado seu primeiro livro de poesia como produção intelectual no concurso da Inspetoria Federal do Ensino certamente ampliou sua circulação em outros circuitos, possibilitando maior respaldo da autoridade intelectual. A sala de aula também foi um local de formação de seus leitores. Além de bancar as publicações de seus livros, ela os distribuía entre amigos, e declamava suas poesias ao final de cada aula, conquistando a partir dessa estratégia um grupo de leitores e admiradores, privilegiadamente feminino, que viria a corroborar com essa imagem e representação da Helena Kolody poetisa.

Posteriormente, ainda em vida, Kolody foi considerada primeira poetisa do Paraná e entre os seus alunos e comunidade educacional paranaense como uma excelente profissional, efetivando assim seu projeto de reconhecimento intelectual conquistado pela competência profissional, uma sólida rede de sociabilidade e uma atuação política entre seus pares. Helena Kolody alcançou tanto prestígio social que seu nome passou a servir de selo de distinção para algumas instituições como o próprio Centro Paranaense Feminino de Cultura e o Instituto Histórico e Geográfico do Paraná que mantém seu nome em seus quadros, embora não tenhamos localizado uma forma efetiva de participação nesses espaços.

\section{REFERENCIAS}

ALMEIDA, J. S. de. Mulher e Educação: A paixão pelo possível. São Paulo: Fundação Editora da UNESP, 1998.

ATAS do Instituto de Educação do Paraná: Exames Finais do curso especial 1930 e 1931. Dados coletados In loco, Arquivo Público do Paraná, Fev. de 2017.

BUENO, W. de. L. Educação das moças na cidade de Curitiba: 1930-47. In VECHIA, A.; CAVAZOTTI, M. A. (Orgs). A Escola Secundária: modelos e planos (Brasil, séculos XIX e XX). São Paulo: Annablume, 2003. 
CHARTIER, R. À beira da falésia: A história entre certezas e inquietude. Porto Alegre: Ed. da Universidade UFRGS, 2002.

COSTA, M. J. F. F. da. A dimensão de um Homem: Lysimaco Ferreira da Costa- o educador. Curitiba: Imprensa da UFPR, 1987.

ENTREVISTA Helena Kolody. Jornal do Livro, nº7, Curitiba, Abr./Mai. de 1985.

GASPARELLO, A. M; VILLELA, H de O S. Intelectuais e professores: identidades sociais em formação no século XIX brasileiro. Revista Brasileira de História da Educação, n 21, p. 39-60, set./dez. 2009

KOLODY, Helena. Entrevista na memória paranaense por José Wille, Curitiba: Fundação INEPAR, 1998.

LEVI, G. Usos da biografia. In: AMADO, J.; FERREIRA, M. de M. (orgs). Usos e abusos da história oral. Rio de Janeiro: Editora FGV, 2006.

LOPES, E. M. T.; GALVÃO, A. M. de O. Território Plural. São Paulo: Ática, 2012.

LOURO, G. L. Mulheres na sala de aula. In PRIORI, M. D. (Org). História das Mulheres do Brasil. São Paulo: Contexto, 1997.

MIGUEL, M. E. B. A Escola Normal no Paraná: instituição formadora de professores e educadora do povo. In: Congresso Brasileiro de História da Educação, $n^{\circ}$ V, 2008. Aracaju. Anais da Sociedade Brasileira de História da Educação: Universidade Tiradentes, 2008, $24 \mathrm{p}$.

Curitiba: Ed da UFPR, 1997.

A formação do professor e a organização social do trabalho.

MILLARCH, A. Quem entrevista Helena Kolody. Revista Quem, nº 29, Curitiba, Out. 1980.

NOTAS biográficas de Helena Kolody. Revista Rumo Paranaense, v.4, Curitiba, Mar. de 1976.

ORLANDO, E. de A. Por uma civilização cristã: a coleção Monsenhor Álvaro Negromonte e a pedagogia do catecismo (1937-1965). São Cristovão, SE: UFS, 2008. Originalmente apresentada como Dissertação de Mestrado em Educação, Universidade Federal de Sergipe, 2008, 297f.

PARANÁ. Revista Helena, Secretaria de Estado da Cultura, ano 1, no zero, Curitiba, Jun. de 2012.

PEDRO, J. M. Mulheres do Sul. In PRIORI, M. D. (Org.). História das Mulheres do Brasil. São Paulo: Contexto, 1997

PERROT, M. Os excluídos da história. Rio de Janeiro: Paz e Terra, 1988. 
ROCHA, D. Escola Normal Secundária de Curitiba nos anos 20. In VECHIA, Ariclê; CAVAZOTTI, Maria Auxiliadora (Orgs). A Escola Secundária: modelos e planos (Brasil, séculos XIX e XX). São Paulo: Annablume, 2003.

SANTOS, D. G. Helena Kolody- a primeira brasileira da família. Caderno do Museu de Imagem e Som do Paraná, nº 13, Curitiba, 25 de Ago. 1989

SIRINELLI, J. F. Os intelectuais. In: RÉMOND, R. (org.). Por uma história política. Rio de Janeiro: Editora UFRJ, 1996.

TRINDADE, E. M. de C. Clotildes ou Marias: mulheres de Curitiba na Primeira República. Curitiba: Fundação Cultural, 1996.

Recebido em: 04.07.2017

Aceito em: 30.11 .2018 